\title{
In reply: Regional anesthesia during the COVID-19 pandemic: a time to reconsider practices? (Letters \#1 and \#2)
}

\author{
Sui An Lie, MBBS, MRCP, MMed (1) - Sook Wai Wong, MBBS • \\ Loong Tat Wong, MBBS, MMed, CHSE - Theodore Gar Ling Wong, MD, \\ FRCPC $\cdot$ Shin Yuet Chong, MBBS, MMed, CHSE
}

Received: 20 April 2020/Accepted: 20 April 2020/Published online: 1 May 2020

(C) Canadian Anesthesiologists' Society 2020

To the Editor,

We thank Drs Soberón ${ }^{1}$ and Aliste $^{2}$ for their letters and appreciate their thoughtful points. The spirit of the practical recommendations put forth in our article ${ }^{3}$ aims to safeguard the well-being and safety of patients and staff, acknowledging that some aspects will need to be adjusted as more knowledge about coronavirus disease (COVID-19) surfaces and international guidelines change in response to new challenges. ${ }^{4,5}$

We mentioned that operators performing regional anesthesia (RA) should at minimum don personal protective equipment, goggles, and a surgical face mask. This was based on the recommendation by the Centers for Disease Control and Prevention to prioritize the use of N95 respirators for aerosol-generating procedures and surgical masks for care that does not involve such procedures. This is applicable given the current challenge faced by some centres with limited supplies of $\mathrm{N} 95$ and other respirators. Otherwise, the use of N95 or higher-level respirators should be used. In fact, this is the recommendation in our institution for performing RA in these patients as we recognize that RA reduces but does not eliminate the risk of spread of aerosols. There is also the potential need for emergent airway intervention during the surgery, or conversion to general anesthesia in the event of block failure or surgical complications.

Secondly, our group agrees that the goal should be a cooperative patient with spontaneous breathing (not

S. A. Lie, MBBS, MRCP, MMed ( $₫) \cdot$ S. W. Wong, MBBS ·

L. T. Wong, MBBS, MMed, CHSE - T. G. L. Wong, MD,

FRCPC $\cdot$ S. Y. Chong, MBBS, MMed, CHSE

Division of Anesthesiology and Perioperative Medicine,

Singapore General Hospital, Singapore, Singapore

e-mail: lie.sui.an@singhealth.com.sg coughing and always wearing a surgical mask). If needed for hypoxemia from COVID-19 pneumonia, supplemental oxygen can be delivered via nasal prongs under the surgical mask. Sedation should be used with caution (or not at all) to avoid worsening underlying respiratory impairment. If sedation were to be considered, dexmedetomidine may be suitable given its minimal effects on respiration. ${ }^{5}$ Respiratory rate can be monitored by clinical observation or electrocardiogram systems that use impedance plethysmography. For completeness, the options of modifying the existing oxygen delivery set-up were presented for readers considering continuous capnography monitoring, although this is not strictly needed. If used, oxygen flow through the face mask should be kept as low as needed to reduce dispersion. Also, avoiding interscalene block to minimize the risk of phrenic nerve palsy is paramount in a respiratory-compromised patient.

Finally, the choice of RA should be decided on a case by case basis based on institutional guidance, balancing risks and benefits, availability of RA expertise and equipment, technical ease of block, patient suitability and cooperativity, and surgical needs.

Disclosures None.

Funding statement None.

Editorial responsibility This submission was handled by Dr. Hilary P. Grocott, Editor-in-Chief, Canadian Journal of Anesthesia.

\section{References}

1. Soberón JR $J r$, Urdaneta $F$. Regional anesthesia during the COVID-19 pandemic: a time to reconsider practices? (Letter \#1). Can J Anesth 2020. DOI: https://doi.org/10.1007/s12630-02001681-w. 
2. Aliste J, Altermatt FR, Atton R, et al. Regional anesthesia during the COVID-19 pandemic: a time to reconsider practices? (Letter \#2). Can J Anesth 2020. DOI: https://doi.org/10.1007/s12630-02001682-9.

3. Lie SA, Wong SW, Wong LT, Wong TG, Chong SY. Practical considerations for performing regional anesthesia: lessons learned from the COVID-19 pandemic. Can J Anesth. 2020. DOI: https:// doi.org/10.1007/s12630-020-01637-0.

4. World Health Organization. Infection prevention and control during health care when novel coronavirus $(\mathrm{nCoV})$ infection is suspected. Available from URL: https://www.who.int/ publications-detail/infection-prevention-and-control-duringhealth-care-when-novel-coronavirus-(ncov)-infection-issuspected-20200125 (accessed April 2020).

5. Weerink MA, Struys MM, Hannivoort LN, Barends CR, Absalom AR, Colin P. Clinical pharmacokinetics and pharmacodynamics of dexmedetomidine. Clin Pharmacokinet. 2017;56:893-913.

Publisher's Note Springer Nature remains neutral with regard to jurisdictional claims in published maps and institutional affiliations. 